\title{
Variegated Glacier, Alaska, USA: a century of surges
}

\author{
Olaf EISEN, ${ }^{1 *}$ William D. HARRISON, ${ }^{1}$ Charles F. RAYMOND, ${ }^{2}$ \\ Keith A. ECHELMEYER, ${ }^{1}$ Gary A. BENDER, ${ }^{1}$ Jeannette L.D. GORDA ${ }^{1}$ \\ ${ }^{1}$ Geophysical Institute, University of Alaska Fairbanks, 903 Koyukuk Drive, Fairbanks, Alaska 99775-7320, USA \\ E-mail: harrison@gi.alaska.edu \\ ${ }^{2}$ Department of Earth and Space Sciences, University of Washington, Seattle, Washington 98195-1310, USA
}

\begin{abstract}
A 1995 surge of Variegated Glacier, Alaska, USA, is discussed in the context of its six 20thcentury predecessors, especially the previous surge in 1982/83 which was studied in detail. The average time between surge initiations is 15 years. The 1995 surge was considerably weaker than its predecessors, having a single phase or at most a very weak second phase. The 1995 surge confirms that there is a seasonal cycle, with surge initiation in winter and termination in the first part of the melt season, and a correlation between weather and both surge termination date and surge extent. Two days of record high temperature correlated with the termination of the 1995 surge. The most obvious issue is the absence of a strong second surge phase (as there was in the 1982/83 surge) culminating in a surge extent more in line with that of the predecessors. This is considered in the light of a simple criterion for surge initiation and re-initiation which depends upon the evolving basal shear stress.
\end{abstract}

\section{INTRODUCTION}

Variegated Glacier, on the coastal side of the St Elias Mountains, Alaska, USA, (Figs 1 and 2) is one of the few extensively studied surge-type glaciers in the world, thanks to a short surge recurrence interval, reconnaissance data beginning in 1895, and a major field study of the evolution of the glacier from 1973 through 1986 (e.g. Bindschadler and others, 1977; Raymond and Harrison, 1988). This study included observations of a surge which occurred in 1982/83 (e.g. Kamb and others, 1985; Raymond, 1987; Raymond and others, 1987; Humphrey and Raymond, 1994; Sharp and others, 1994). A subsequent surge in 1995 is therefore of special interest, especially since it was quite different from its predecessors. In this paper, we describe this surge in the context of the other six surges of the 20th century and discuss some of the implications.

\section{SURGE HISTORY}

Post (1969), Bindschadler and others (1977), G. Bender (unpublished information, 1983) and Lawson (1997) have discussed the history of surges during the 20th century. An updated version of Lawson's version of the history, used by Eisen and others (2001), is also used here. It is summarized by the time line and the naming of the surges in Figure 3, and by the final positions of the surge fronts in Figure 4. Differences from the Lawson version are explained in the Appendix. Here we give a brief summary of the methods that have been used and supply previously unreported documentation for some of the surges.

The surge history is constrained by field observations in 1905/06, 1973-86 and 1995/96, and by a number of photographs (both vertical and oblique) in which the much larger Hubbard Glacier was often the primary target. Three examples of oblique photos chosen from among the most difficult to find are shown in Figure 5. Figure 5a, the earliest

*Present address: Versuchsanstalt für Wasserbau, Hydrologie und Glaziologie, Eidgenössische Technische Hochschule, ETH-Zentrum, CH-8092 Zürich, Switzerland.

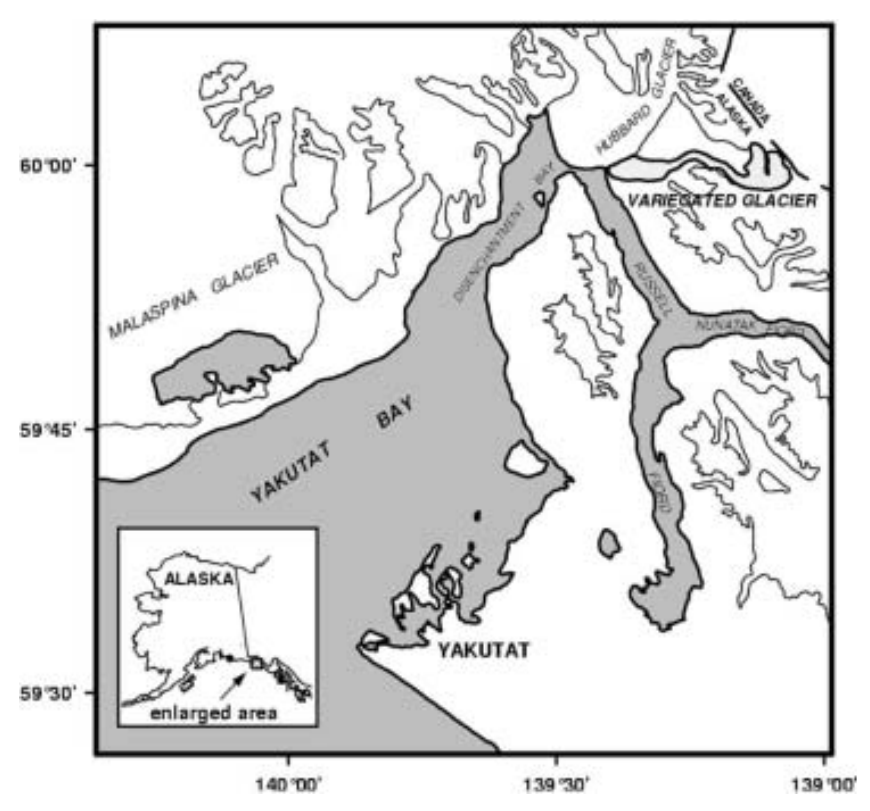

Fig. 1. Location of Variegated Glacier.

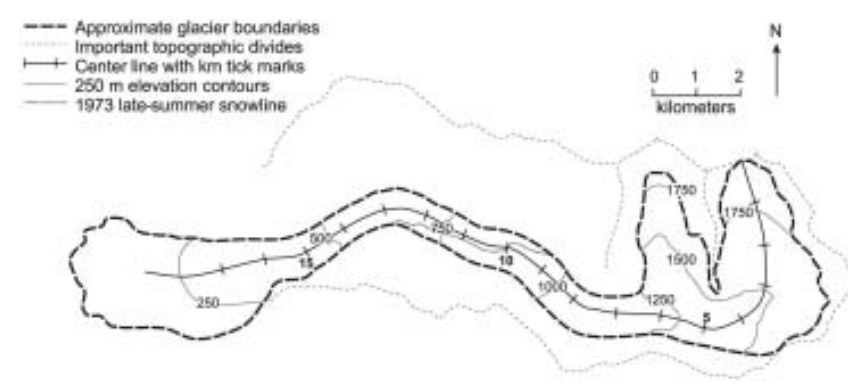

Fig. 2. Map of Variegated Glacier with kilometers from glacier head indicated by tick marks. The direction of flow is from east to west. Topography $(\mathrm{m})$ is sketched from maps based on 1948 and 1961 photography. 


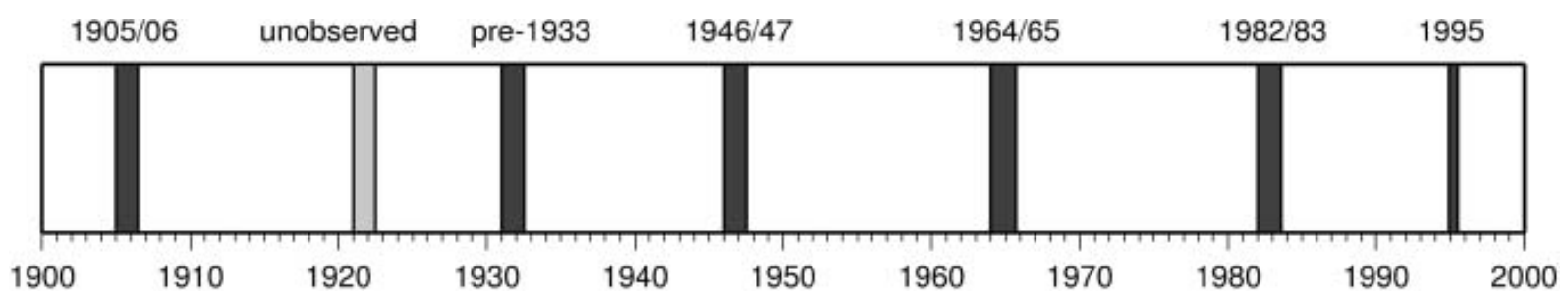

Fig. 3. Time line of surges from Eisen and others (2001). The width of the dark bars indicates the estimated total surge duration, which is well known only for the last two surges. The light bar in 1922 is the best estimate of the dating based on mass-balance correlation.

photo known to us, shows how at least some of the 19thcentury surges extended all the way to Russell Fiord, although it does not provide any useful dates. This area is being overrun by the advancing Hubbard Glacier (Fig. 4). Figure 5b shows the evidence for the 'pre-1933 surge', and illustrates the difficulty of determining the exact position of the 'surge front' from such oblique photos, even when it is reasonably well defined by a topographic step or a discontinuity in the intensity of crevassing. In our nomenclature, the final position of this front defines the 'extent' of a surge. Another difficulty is determining the exact timing from the limited photographic record. In the pre-1933 example, the 'freshness' of the crevassing and the step suggest a recent surge, while a 1934 photo indicates that the surge was already complete when the 1933 photo was taken. Figure $5 \mathrm{c}$ shows that no surge occurred in the years immediately prior to 1942 .

There is no known photography between 1911 and 1932 . The mass-balance considerations of Eisen and others (2001) suggest that a surge (the 'unobserved surge') began within about 3 years of 1922 . They point out the possibility that this surge, like the 1995 surge described below, was relatively 'weak' in the sense that it had a relatively small extent.
The duration of individual surges, as shown by the width of the lines in Figure 3, is known only for the 1982/83 and 1995 surges. In the former case, the surge duration included two distinct phases separated by about 3 months of relative quiescence. For the other surges, the duration of the 1982/83 surge is assumed. If early-melt-season termination of surge phases is universal, photographic observations during and after the 1964/65 surge (personal communication from A. Post, 1973; Paterson, 1994) indicate that it, at least, also had two phases.

Despite the uncertainties, the surge history is remarkably well constrained considering that the historical record is relatively short and observations are sparse. Possibly there were other surges which were unobserved because, like the 1995 surge described in detail below, they had only a small effect on the lower glacier. However, the completeness of the history as it stands is supported by the connection between timing and balance discussed by Eisen and others (2001). During the 20th century there was a 13-18year interval between surge initiations, with the possible exception of the 'unobserved surge'. The average time between surge initiations was 15 years.

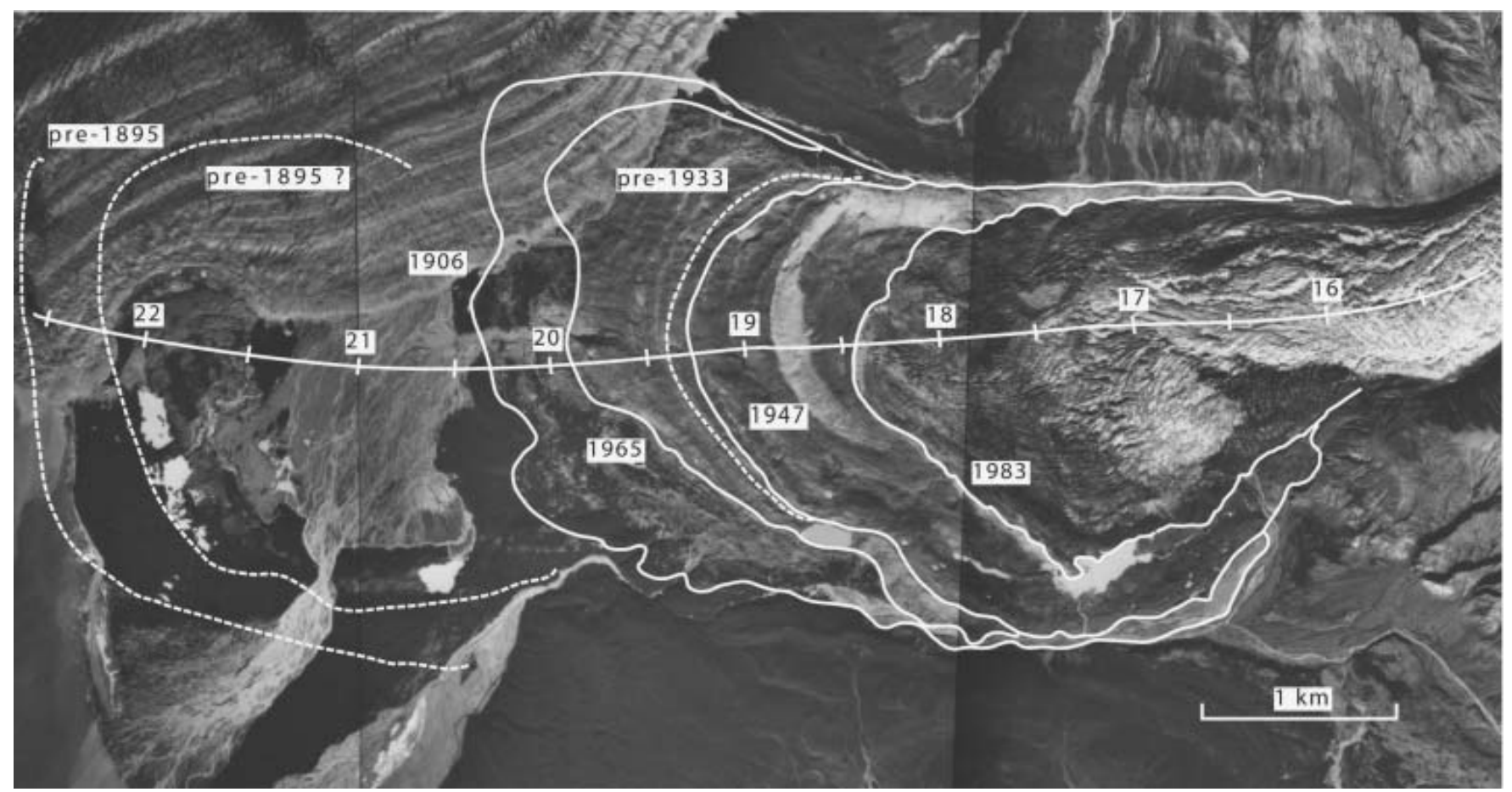

Fig. 4. 1983 (28 August) composite vertical photo showing the final positions of the pre-1995 surge fronts (AeroMap US for University of Alaska). Hubbard Glacier is at the upper left. The front for the pre-1933 surge is dashed because of uncertainty in its position. The marks on the center line indicate kilometers from the head of the glacier. The poorly defined 1995 surge front is out of the picture at about $12 \mathrm{~km}$. 

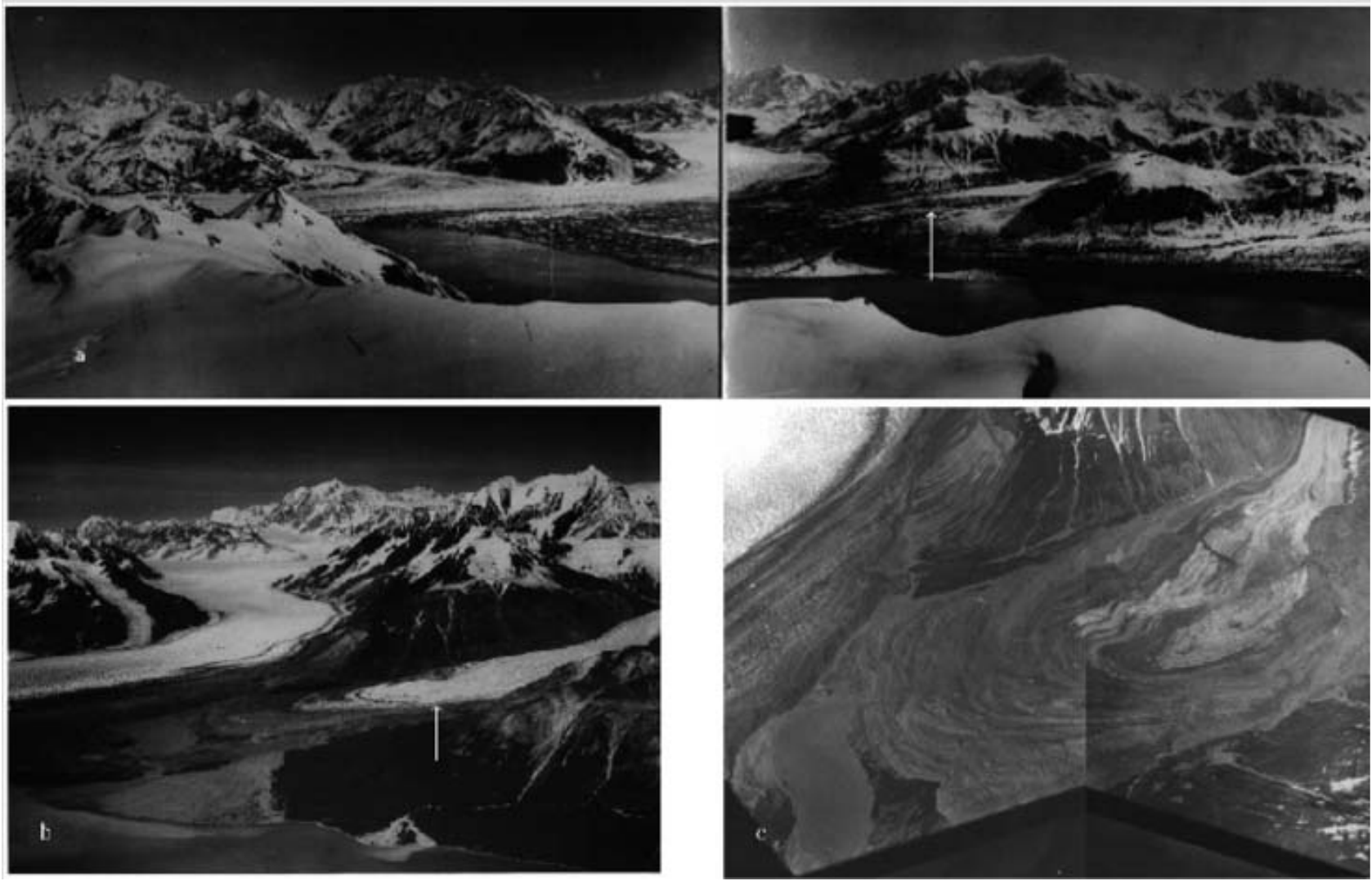

Fig. 5. Historical photos of Variegated Glacier (arrows). (a) 1895 photo pair from Mount Alexander on the western side of Russell Fiord. Variegated Glacier emerges from the mountains in the center of the right panel (white arrows), becomes covered with debris and continues to the fiord. Hubbard Glacier is in the background (A.J. Brabazon, B-18-95 and B-19-95). (b) 1933 aerial oblique photo (B. Washburn, $5 \times 7: 2573$ ). (c) 1942 aerial oblique photo taken with a nine-lens camera (from A. Bodnar, US National Oceanic and Atmospheric Administration).

\section{THE 1995 SURGE}

Starting in September 1994, oblique photos from the air and ground, and one set of aerial verticals, were obtained at variable intervals on Variegated Glacier. The most frequent coverage was in summer 1996. A sample aerial photo from 16 January 1996 is shown in Figure 6. The glacier was visited from 9 to 11 June 1995, when two time-lapse cameras were deployed, and from 25 to 26 May 1996. Detailed center-line surface elevation profiles were measured by airborne methods (accurate to about $0.3 \mathrm{~m}$ with measurement points spaced at roughly $1 \mathrm{~m}$ intervals) (Echelmeyer and others, 1996) on 5 June 1995, 5 June 1996, 23 June 2000 and 28 August 2000. The 1995 and 1996 data are shown in Figure 7.

On 6 September 1994 the state of surface crevassing as seen from the air was reminiscent of that before the 1982/83 surge. The sheared margins characteristic of active surging had not yet developed. However, by 7 June 1995, intense crevassing in the upper glacier indicated that a surge had begun well before then, most likely in winter 1994/95, but possibly earlier, in autumn. A poorly defined feature that could possibly be called a 'surge front' could be seen at about $12 \mathrm{~km}$ from the head of the glacier near the location of a small icefall. However, sheared margins extended about $3 \mathrm{~km}$ farther down-glacier, and crevassing, moderate but more intense than during quiescent conditions, extended to roughly $17 \mathrm{~km}$. It is difficult to base quantitative statements on the oblique photography since the photos were taken from different positions and with different lighting and snow cover. However, the surface conditions sketched by field personnel on 10 June 1995 are quite similar to those in the 16 January 1996 photograph in Figure 6, although we shall see that conditions may have been slightly different. In particular, some of the thickening and crevassing evident near the margins may have developed after 10 June 1995.

The surface elevation profiles (Fig. 7) show an impressive post-surge overall thinning of Variegated Glacier between 5 June 1995 and 5 June 1996, except for a conspicuous area of thickening of up to $20 \mathrm{~m}$ which occurred from about 12

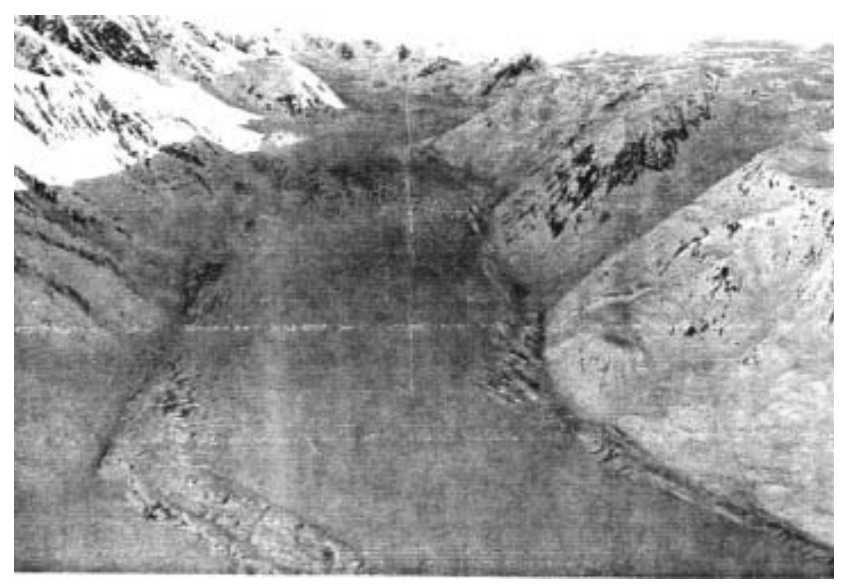

Fig. 6. 1996 (16 January) aerial oblique photo (Gulf Air Taxi for University of Alaska). 


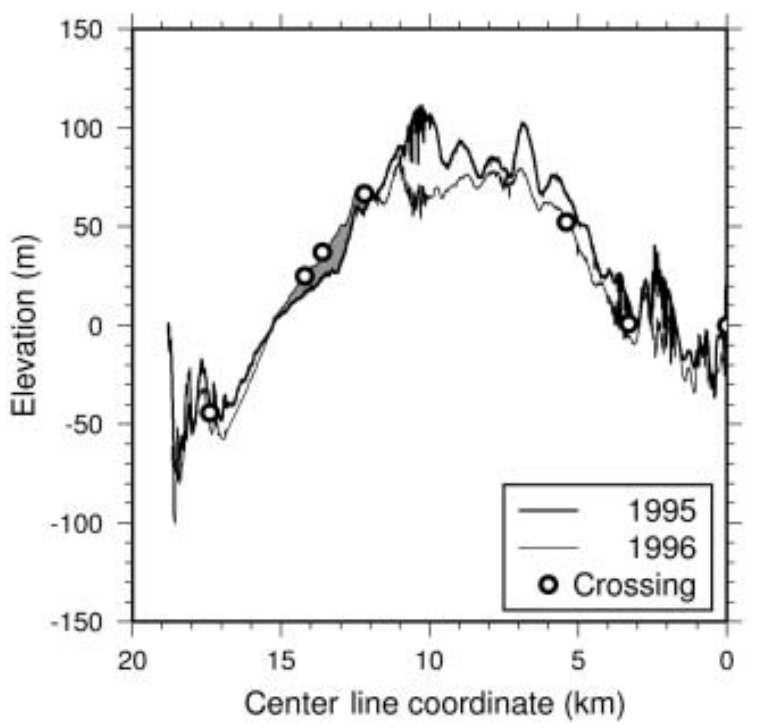

Fig. 7. Center-line surface elevations for 5 June 1995 and 5 June 1996 obtained by airborne profiling. All elevations are referenced to elevation in September 1973. Crossover points, where the ground tracks of the two years crossed, are shown by the circles. The shading indicates the area of thickening between 1995 and 1996. The fine structure is due to heavy crevassing.

to $15 \mathrm{~km}$. The region of thickening is highlighted by shading between the curves for these years. (The thickening interpretation is not biased significantly by differences in the ground track of the aircraft in those years, because there were several crossover points, as indicated in the figure.) The thickening occurred immediately down-glacier from the poorly defined surge front of 1995 .

On 11 June 1995 a major flood occurred in the main stream (stream 2 of Humphrey and Raymond, 1994). It is significant that this occurred after the two hottest days in Yakutat (the location of the nearest weather station; Fig. 1) since records began in 1917. The evidence for the flood was a lake that formed in the early morning in the terminal area. It disappeared after several hours, leaving a thick deposit of mud. No subsequent surge activity was detected by the aerial and time-lapse photography, perhaps because of the limitations noted above. Nevertheless, subsequent thickening occurred between 12 and $15 \mathrm{~km}$ as just discussed.

There are two end-members in the spectrum of possible interpretations for the evolution of the surge. The first is that 11 June 1995 was the termination date, or perhaps somewhat later if there was a complex termination phase of floods and deceleration and acceleration events as seen in 1983 on this glacier and at the termination of West Fork Glacier (Harrison and others, 1994). In this case, the subsequent thickening downstream of the poorly defined surge front could have taken place during this phase or even by normal flow processes promoted by the large shear stress as described below. The second end-member is that the surge did terminate but re-initiated in the sense that the subsequent thickening was due to a more-or-less distinct second phase of the surge. However, if there was a reinitiated surge phase it did not propagate far or with a welldefined front; a major second phase of the surge is ruled out by the time-lapse and aerial photography through the year 2000. Finally, relic crevasses could still be seen low on the glacier on 28 August 2000, which is rather surprising considering the $10 \mathrm{~m}$ of annual ablation there. However, no horizontal displacement of surface features since 1995 was evident in our admittedly low-resolution photographic observations. The difference between the two end-member interpretations of surge progression may depend in part upon the definition of the word 'surge'; there certainly was 'activity' after the 11 June 1995 flood.

\section{COMPARISON OF THE 1995 WITH THE 1982/83 AND EARLIER SURGES}

\section{Time between surges}

The 1995 Variegated Glacier surge occurred about 12.5 years after the 1982/83 surge terminated, while the previous two surges began about 17 years after their predecessors terminated. Recall that the period measured between surge terminations or initiations is slightly longer because of the finite duration of the surges. As noted above, the period has an average of 15 years between the initiations of the seven surges of the 20th century. This period has no discernible trend in time.

\section{Number of phases}

Most of the activity of the 1995 surge was during a single phase, although as discussed above, the existence of a very weak second phase seems possible. The 1982/83 surge had two phases, each with a reasonably distinct termination separated by 1 year. The number of phases in earlier surges is uncertain, as noted above, although there is evidence that the 1964/65 surge had two phases.

\section{Seasonal timing}

The seasonal timing of the 1995 surge seems to have been the same as both phases of the 1982/83 surge. Thus the seasonal cycle, initiation in winter or late autumn and termination in late spring or early summer, was the same.

\section{Extent}

The 1995 surge was relatively weak, having a much smaller effect on the lower glacier than all of its predecessors, with the possible exception of the 'unobserved surge' around 1922. Although the comparison is somewhat subjective, the extent of the 1995 surge, as estimated by the position of a poorly defined surge front around $12 \mathrm{~km}$, was roughly $2 \mathrm{~km}$ greater than that of the first phase of the 1982/83 surge, as estimated from the position of a similar poorly defined front. It is seen in Figure 4 that the surges become progressively weaker through the 20th century, with the notable exception of the 1964/65 surge.

\section{Crevassing}

At the termination of the 1995 surge, crevassing in the upper part of the glacier (above the $12 \mathrm{~km}$ front) was more intense than at the end of the first phase of the 1982/83 surge, but similar to that at the end of the second phase.

\section{Surface elevation}

Unfortunately, we do not have surface elevation data preceding the 1995 surge, but in Figure 8 the elevations near or at the 1995 termination are compared with those at the termination of both phases of the 1982/83 surge (curves labeled 95, 82 and 83). The elevation distribution at the 1995 termination was very different from those at the 


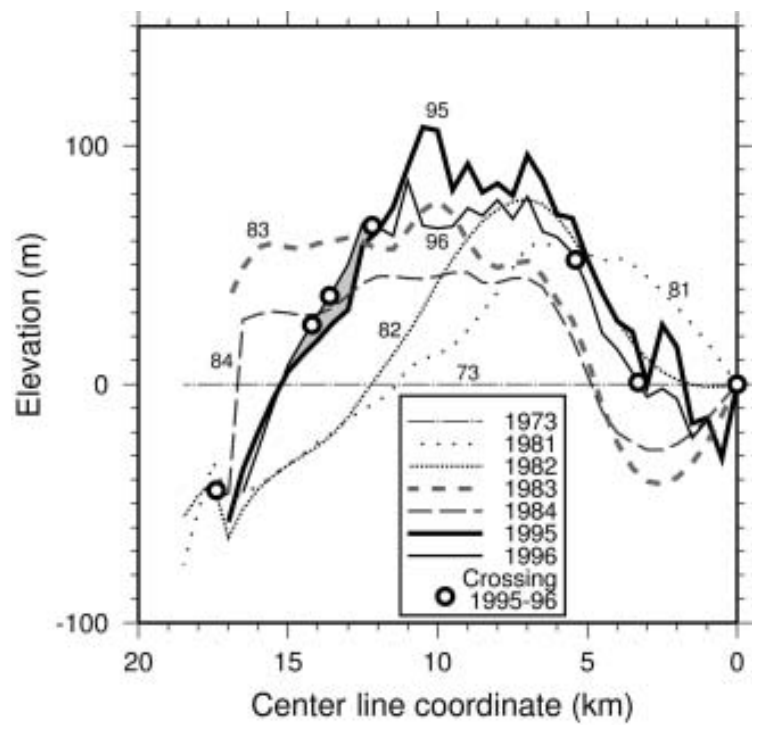

Fig. 8. Center-line elevation profiles for important years, referenced to elevation in September 1973. All profiles were measured in September, except for those in 1995 and 1996, which were measured in June. The 1995 and 1996 airborne data have been smoothed for clarity; the circles are crossover points. Measurements by conventional surface methods in other years have been interpolated. The shading indicates the area of thickening between 1995 and 1996.

terminations of both phases of the 1982/83 surge, although there is some similarity with the 1982 termination in the upper glacier. In 1995 the elevation of the lower glacier was greater than it was in 1982 after the termination of the first phase of the 1982/83 surge, which reflects the greater development of the 1995 surge.

Both the 1995 and the 1982/83 surges show a large thinning of the glacier 1 year after termination, which is at least partially due to the closure of crevasses. This can be seen by comparison of the curves labeled 95 and 96 in Figure 8, and the pair labeled 83 and 84. (See also Figure 7.) The first comparison is complicated by activity leading to local thickening after the 11 June 1995 flood, as noted above, but the general trend is still clear.

\section{Stream discharge}

The flood of turbid water at the 1995 nominal termination was reminiscent of the floods seen during the termination of both phases of the 1982/83 surge. Those terminations were complex, with several abrupt changes in speed accompanied by floods of turbid water. The complexity of the 1995 termination is not constrained by our observations.

\section{Shear stress}

A standard but crude approximation for the basal shear stress, $\tau$, (Fig. 9) was used: $\tau \approx F \rho g h \sin \alpha$, in which $F$ is a shape factor, $\rho$ is the density, $g$ is the gravitational acceleration, $h$ is the thickness and $\alpha$ is the surface slope. It was calculated from measurements of surface elevation at stakes in 1973, 1981, 1982, 1983 and 1984, and from airborne profiling in 1995 and 1996. The bed profile given in Raymond (1987) was used. Surface slope was calculated over $1 \mathrm{~km}$ segments of surface topography. A shape factor of 0.5 and an average relative density of 0.9 were assumed, and no correction was made for the decrease in average

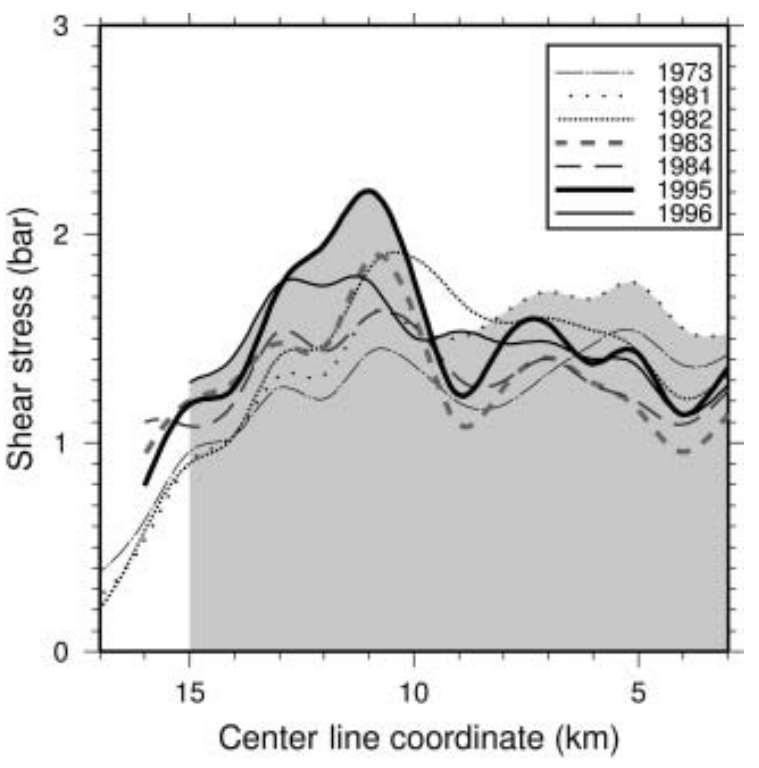

Fig. 9. Estimated basal shear stress $\tau$ for several years $(1 \mathrm{bar} \approx$ $10^{5} \mathrm{~Pa}$ ). The surface slope is calculated for $1 \mathrm{~km}$ intervals. The shaded area underlies the composite curve, made from the highest of the 1981, 1983, 1995 and 1996 curves; it is a lower limit on the critical shear stress, $\tau_{\mathrm{C}}$, assuming no re-initiation of the 1995 surge. Other constraints on $\tau_{\mathrm{C}}$ are discussed in the text.

density due to heavy crevassing in surge years. It is notable that the post-surge stress was higher in 1995 than in 1984. The stress in the vicinity of $11 \mathrm{~km}$ in June 1995 was so high that 'normal' flow processes, as opposed to surge reinitiation, could possibly account for the subsequent thickening between 12 and $15 \mathrm{~km}$ discussed above in connection with Figure 7. However, high shear stress also seems to promote surge initiation, as discussed below.

\section{TIMING, CLIMATE, WEATHER AND SURGE EXTENT}

One of the more striking patterns in the 20th-century Variegated Glacier surges is the correlation between the timing of surge initiation and the cumulative balance at a point in the accumulation area since the termination of the previous surge (Eisen and others, 2001). The balance-timing correlation could be due to the filling of the upper part of the glacier to a critical level (realizing that there is also a flow component to thickness change), where it is known that some surges, and possibly all of them, initiate. This filling, in turn, could be a proxy for basal shear stress, an important quantity as discussed below. The correlation holds despite climatically induced changes in the size of the glacier since 1900, possibly because the upper glacier (in common with non-surging glaciers) has not been affected much by climate change (Harrison and Post, 2003). The existence of the correlation suggests that the drawdown in the upper basin during previous surges has been similar for all the pre-1995 surges, although the data are limited. Eisen and others (2001) noted that because drawdown in the upper glacier during the 1995 surge was typically $20 \mathrm{~m}$ less than in the previous surge (Fig. 8), the correlation may break down for the next surge.

There is a seasonal pattern of surge initiations and terminations, undoubtedly related to the abundance of surface water. As noted above, a significant aspect of the termination of the 1995 surge is that it occurred after the two 


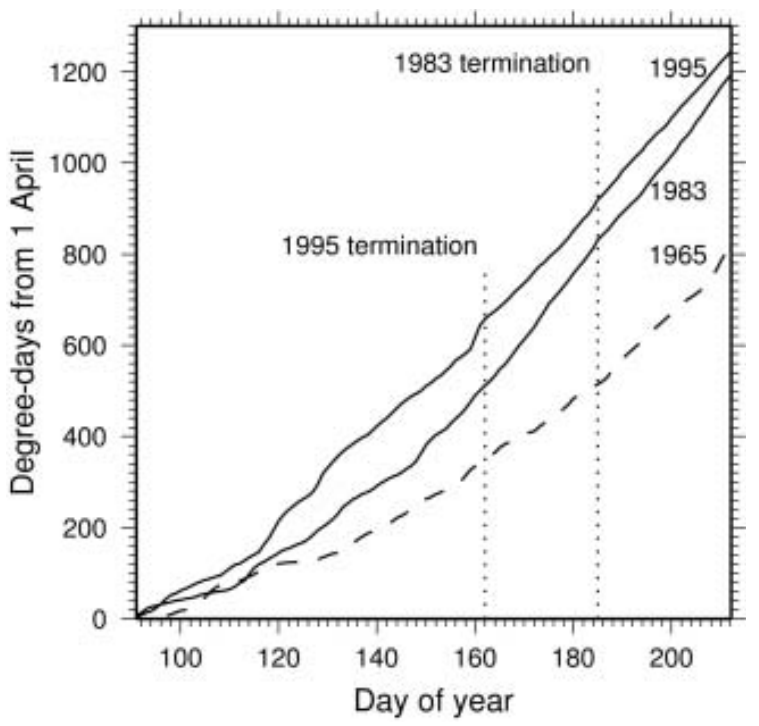

Fig. 10. Degree-day plots (starting 1 April) for surges terminating in 1965 (dashed line), 1983 and 1995 (solid lines). The known dates of termination are indicated by the vertical dotted lines.

hottest days in the 78 year Yakutat record. Field personnel experiencing this weather predicted the imminent termination, remembering that the 1982/83 surge had also terminated in the melt season, probably because water entering from the surface triggered an abrupt shift from an inefficient distributed subglacial drainage system to an efficient channelized system (Kamb and others, 1985; Raymond, 1987). Most of the few dated terminations in Alaska have occurred in the melt season. Other examples are the single-phase surge of West Fork Glacier in July 1988 (Harrison and others, 1994), and the two phases of a Bering Glacier surge in July 1994 and summer 1995 (e.g. Lingle and Fatland, 2003). The correlation is not universal since the 1986/87 surge of Peters Glacier probably terminated in winter (Echelmeyer and others, 1987). Nevertheless, a correlation between termination and weather is more convincing in the light of the termination of the 1995 surge. Most of the Alaska surges are known to have begun after the melt season. Thus the most common pattern is a seasonal cycle in which initiation tends to occur in winter and termination in the melt season.

A property of the surges noted above is the decrease in surge extent throughout the century, which is probably associated with climate and the decreasing size of the glacier. The exception is the 1964/65 Variegated Glacier surge (whose exact termination date is unknown). It is plausible that its extent was due to cool weather in the first part of the melt season (Harrison and Post, 2003); since there is a correlation between termination date and weather, there should also be a correlation between weather and surge extent. However, one might expect the latter correlation to be poorer because other factors (such as the progress of a surge prior to the melt season) must be involved. Since on this glacier most of the surface water in the first part of the melt season comes from melting, a cumulative degree-day plot of temperature should be a rough proxy for water availability. This is shown in Figure 10, together with the known final termination dates. Of the three years, 1995 was the warmest, 1983 was cooler, and 1965 distinctly the coldest. This is suggestive that a cool melt season may indeed have been a factor in the extent of the 1964/65 surge. This conclusion is not changed if the starting date for the degree-day sum is changed by 1 month, but the correlation does not apply in any simple way to the first phase of the $1982 / 83$ surge.

Although generally cool weather may indeed be the reason for the late termination and large extent of the 1964/ 65 surge, it does not follow that generally warm weather is solely responsible for the early termination of the 1995 surge. The two record hot days preceding termination (evident in the steepness of the degree-day curve just before termination) are probably at least as important as the average represented by the degree-day sum.

\section{WHY WAS THE 1995 SURGE DIFFERENT?}

The most obvious question arising from the observations is why the 1995 surge was so different from all its predecessors (with the possible exception of the unobserved surge around 1922). If it had not been for the two hot days, the surge might have terminated later and had a greater extent, but given the surge-front propagation speeds seen in the previous surge (Raymond and others, 1987), it is unlikely that even then the extent of the earlier surges would have been approached in 1995, at least under the constraint that surges terminate in the first part of the melt season. The question then becomes why there was not a re-initiation of the 1995 surge leading to a major second phase, as there was for its predecessor. It was a second phase in 1982/83, and possibly other years, such as $1964 / 65$, that led to the relatively large surge extents more typical of the 20th century.

\section{A mechanism for surge initiation}

To discuss the re-initiation question, we use a hypothesis about the seasonal cycle of surge initiation, elements of which also apply to the seasonal pattern of motion observed in most glaciers (e.g. Raymond, 1987; Lingle and Fatland, 2003). The basic idea is that the evolving topography of a surge-type glacier affects the internal drainage system, and that a point may be reached late in a melt season at which there is insufficient water flow to keep the system open. Subsequent rain or meltwater from the surface would be trapped within the glacier. The greater density of water relative to ice would then allow this water to be pumped to the bed under high pressure, weaken the bed and promote a surge, probably in winter (as observed) because some time should be required for the water redistribution. The process is discussed briefly by Raymond and Harrison (1986) and Raymond (1987), and there are several other relevant discussions (e.g. Humphrey and Raymond, 1994; Fountain and Walder, 1998; Harrison and Post, 2003; Lingle and Fatland, 2003). The surge would end in spring or summer when the input of surface water becomes sufficient to open and maintain the drainage system. Once a surge is initiated in some region, it is easy to imagine how the blockage of the drainage system and stress redistribution could allow the region first affected to grow.

The idea of drainage loss can be illustrated using a crude model in which water is carried subglacially in one or a few conduits over a 'hard' (rigid) bed; fluctuations in normal stress occur about protuberances. Leakage from a conduit begins on the downside of the protuberances when the shear stress $\tau$ increases to the point that

$$
\tau=\zeta(P-p)
$$


in which $P$ is the overburden, $p$ is the water pressure in the conduit, and $\zeta$ is a bed roughness parameter. If the overall water flow is declining (as it will be late in the melt season) and conduit leakage commences, the decrease in flux from the leakage will lead to higher conduit pressure according to the Röthlisberger (1972) steady-state theory for a full conduit. This would cause still more leakage and destruction of the conduit. A more complete discussion would require the application of a transient version of the theory. According to a simplified version of the steady-state theory (Paterson, 1994, p. 117),

$$
P-p=c(\sin \beta)^{a} Q^{b},
$$

where $Q$ is the water flux, $\beta$ is the bed slope, $c$ is a quantity that depends upon hydraulic and ice-flow parameters, $a \approx 1 / 2$ and $b \approx 1 / 12$. Combination of Equations (1) and (2) gives the criterion for onset of leakage

$$
\tau=C Q^{b}
$$

where

$$
C \equiv c \zeta(\sin \beta)^{a} .
$$

$C$ represents ice, bed and hydraulic properties, which like $\tau$ vary along the glacier. Equation (3) says that as long as

$$
Q>\left(\frac{\tau}{C}\right)^{\frac{1}{b}}
$$

the conduits stay open. Otherwise they will be lost or replaced by a less efficient drainage system; there is good evidence for both of these outcomes (e.g. Kamb and others, 1985; Harrison and others, 1994; Björnsson, 1998).

An impressive feature of Equation (5) is that $1 / b \approx 12$, so the flux required to preserve the conduits is an extremely sensitive function of the evolving $\tau$. For sufficiently low $\tau$ the base flow from sources such as strain heating and geothermal heat may suffice to keep the conduits open throughout the winter, or at least until a time in early winter when there is no more surface water input to be trapped. However, at some point an increasing $\tau$ may cause conduits to be lost while the melt season is still in progress, with the consequent trapping of water and the events described above.

Since Equation (5) is based on a particular model, it should not be taken literally, but rather as suggestive of the extreme sensitivity of the drainage system to the evolving basal shear stress. It is especially limiting that Equation (5) arises from a hard-bed model, which is not favored by existing observations. Nevertheless it seems quite possible that a similar result holds over 'soft' (deformable) beds as well, although the parameters would have different meanings because of the different physics (e.g. Fowler, 1987). A soft-bed model analogous to our hard-bed version remains to be worked out, but two points are of interest. First, it is likely that loss of the drainage system, either directly or indirectly via failure of the substrate itself, involves the effective normal stress $P-p$ as in Equation (1), although the roughness parameter $\zeta$, at least, would have some other meaning. Second, there are theoretical reasons to expect that Röthlisberger conduits can exist over soft beds, at least under valley glaciers (Walder and Fowler, 1994), which would justify the use of some version of Equation (2). We thus postulate that some version of Equation (5) also applies in the soft-bed case or, in other words, that the basal shear stress is a critical quantity in surge initiation for hard, soft or mixed beds. It is wise to admit some other limitations in the application below, such as the entry of a tributary at about
$6 \mathrm{~km}$, and the assumption of time-independent bed properties. Nevertheless, the simplicity of this approach makes it useful.

\section{Application to Variegated Glacier}

The basal shear stress, $\tau$, (or more realistically the standard approximation for it) is plotted for several years in Figure 9. If we had enough information, we could calculate the critical shear stress $\tau_{\mathrm{C}}$ for surge initiation from Equation (3) and plot it as well, thereby allowing a test of whether surges have begun when and where $\tau>\tau_{\mathrm{c}}$. Since this is not possible, we use the observations to put constraints on $\tau_{\mathrm{C}}$, and see what can be learned in the process. First note that the glacier was stable in 1981 just before the 1982/83 surge, stable after completion of the second phase of the surge in 1983, and stable in 1996. If we adopt the point of view that the glacier was stable after the 1995 surge (no re-initiation, an uncertainty discussed above), then $\tau_{\mathrm{c}}$ must everywhere lie above a curve that is the highest of the 1981, 1983, 1995 and 1996 curves. This 'composite' curve is indicated by the shading that underlies it in Figure 9. Thus the first constraint is that the $\tau_{\mathrm{c}}$ curve lies above this curve everywhere.

It is possible to put other constraints on the $\tau_{\mathrm{c}}$ curve. It is seen in Figure 9 that the 1982 curve lies below the composite curve down to about $8.3 \mathrm{~km}$ from the head of the glacier, where they cross. But since we know the surge re-initiated in fall 1982, the 1982 curve must also cross the $\tau_{\mathrm{c}}$ curve (at least once) somewhere below $8.3 \mathrm{~km}$. However, because the 1982 curve lies above the composite 1981/ 1983 curve only down to about $10.3 \mathrm{~km}$, the crossing must have been in this interval $(8.3-10.3 \mathrm{~km})$. We also know that $\tau_{\mathrm{c}}$ is close to the composite curve on the upper part of the glacier (where the composite and 1981 curves are identical), because in 1981 the surge was about to initiate there, probably near or above $6 \mathrm{~km}$ (Raymond, 1987). The situation would be more complicated if in fact there were a reinitiation after 1995. Then there could be more than one crossing of the 1995 and composite curves, and thus more than one candidate location for surge re-initiation.

Although this exercise in surge initiation is very simple in principle, it is convoluted in practice. This illustrates that reinitiation of a surge is a delicate matter which depends upon the details of the shape of the glacier upon termination of a first surge phase. It may also depend upon other things, such as evolving bed conditions or the exact seasonal timing of the loss of the drainage system. This would affect the amount and distribution of stored water (e.g. Lingle and Fatland, 2003), and could account for the differences in the earliest phases of the 1995 and 1982/83 surges. One can even speculate that the unusually hot weather which promoted the relatively early termination in 1995 was a factor inhibiting a major re-initiation. Thus the hot weather, although not accounting for the failure of the surge in 1995 to reach the extent of its predecessors, could have had the same effect indirectly by terminating the first phase when the surface topography was unfavorable for re-initiation.

Finally, the observations bearing on the important issue of bed morphology merit review. Harrison and Post (2003) summarize evidence which indicates that the bed is soft under at least part of Variegated Glacier, and that soft-bed morphology is a necessary condition for surging in western North America. If this is indeed so, several key issues such as subglacial hydraulics, sliding vs bed deformation, ice-bed separation, extremely high rates of production of eroded 
materials during surges, and mass balance of the subglacial sediments remain to be reconciled.

\section{ACKNOWLEDGEMENTS}

We are grateful to A. Bodnar, M. Miller, A. Post, B. Washburn and $\mathrm{E}$. Wood for help in obtaining historical photographs. Useful comments by J.S. Walder (Scientific Editor) and two anonymous referees are acknowledged. Support was received from the US National Science Foundation, grants OPP-9977796, OPP-9876421 and OPP-0327067.

\section{REFERENCES}

Bindschadler, R., W.D. Harrison, C.F. Raymond and R. Crosson. 1977. Geometry and dynamics of a surge-type glacier. J. Glaciol., 18(79), 181-194.

Björnsson, H. 1998. Hydrological characteristics of the drainage system beneath a surging glacier. Nature, 395(6704), 771-774.

Echelmeyer, K., R. Butterfield and D. Cuillard. 1987. Some observations on a recent surge of Peters Glacier, Alaska, USA J. Glaciol., 33(115), 341-345.

Echelmeyer, K.A. and 8 others. 1996. Airborne surface profiling of glaciers: a case-study in Alaska. J. Glaciol., 42(142), 538-547.

Eisen, O., W.D. Harrison and C.F. Raymond. 2001. The surges of Variegated Glacier, Alaska, USA, and their connection to climate and mass balance. J. Glaciol., 47(158), 351-358.

Fountain, A.G. and J.S. Walder. 1998. Water flow through temperate glaciers. Rev. Geophys., 36(3), 299-328.

Fowler, A.C. 1987. A theory of glacier surges. J. Geophys. Res., 92(B9), 9111-9120.

Harrison, W.D. and A.S. Post. 2003. How much do we really know about glacier surging? Ann. Glaciol., 36, 1-6.

Harrison, W.D., K.A. Echelmeyer, E.F. Chacho, C.F. Raymond and R.J. Benedict. 1994. The 1987-88 surge of West Fork Glacier, Susitna Basin, Alaska, USA J. Glaciol., 40(135), 241-254.

Humphrey, N.F. and C.F. Raymond. 1994. Hydrology, erosion and sediment production in a surging glacier: Variegated Glacier, Alaska, 1982-83. J. Glaciol., 40(136), 539-552.

Kamb, B. and 7 others. 1985. Glacier surge mechanism: 19821983 surge of Variegated Glacier, Alaska. Science, 227(4686), 469-479.

Lawson, W. 1997. Spatial, temporal and kinematic characteristics of surges of Variegated Glacier, Alaska. Ann. Glaciol., 24, 95-101.

Lingle, C.S. and D.R. Fatland. 2003. Does englacial water storage drive temperate glacier surges? Ann. Glaciol., 36, 14-20.

Miller, M.M. 1955. Observations on the regimen of glaciers in the Yakutat Bay region, Alaska 1946-1947. Seattle, WA, Foundation for Glacier Research.

Paterson, W.S.B. 1994. The physics of glaciers. Third edition. Oxford, etc., Elsevier.

Post, A. 1969. Distribution of surging glaciers in western North America. J. Glaciol., 8(53), 229-240.

Raymond, C.F. 1987. How do glaciers surge? A review. J. Geophys. Res., 92(B9), 9121-9134.

Raymond, C.F. and W.D. Harrison. 1986. Winter initiation of surges. [Abstract.] Eidg. Tech. Hochschule Zürich. Versuchanst, Wasserbau, Hydrol. Glaziol. Mitt. 90, 85-86.

Raymond, C.F. and W.D. Harrison. 1988. Evolution of Variegated Glacier, Alaska, USA, prior to its surge. J. Glaciol., 34(117), 154-169.

Raymond, C., T. Jóhannesson, T. Pfeffer and M. Sharp. 1987. Propagation of a glacier surge into stagnant ice. J. Geophys. Res., 92(B9), 9037-9049.

Röthlisberger, H. 1972. Water pressure in intra- and subglacial channels. J. Glaciol., 11(62), 177-203.
Sharp, M., J. Jouzel, B. Hubbard and W. Lawson. 1994. The character, structure and origin of the basal ice layer of a surgetype glacier. J. Glaciol., 40(135), 327-340.

Tarr, R.S. and L. Martin. 1914. Alaskan glacier studies of the National Geographic Society in the Yakutat Bay, Prince William Sound and lower Copper River regions. Washington, DC, National Geographic Society.

Walder, J.S. and A. Fowler. 1994. Channelized subglacial drainage over a deformable bed. J. Glaciol., 40(134), 3-15.

\section{APPENDIX}

\section{SURGE HISTORY UPDATE}

Our analysis of the Variegated Glacier surge history draws upon the same materials used by several investigators including Lawson (1997). However, for two particular surges we draw conclusions different from hers, concerning the final position of the surge front in 1906, and the year of termination of the surge which took place in the 1940s.

\section{The 1905/06 surge}

The surge activity of Variegated Glacier was first noticed during the expeditions of the US National Geographic Society to the Yakutat Bay area, during which a surge was documented. In August 1905 the lower part of the glacier was traveled to roughly $13 \mathrm{~km}$ from the head, and was found to be smooth (Tarr and Martin, 1914). By August 1906 it had thickened and was heavily crevassed. Lawson (1997) suggested that this surge terminated at $21.5 \mathrm{~km}$. This is not supported by Tarr and Martin's description or by subsequent photos. According to Tarr and Martin, the surge front encroached upon and narrowed the alluvial 'interior flat', where it is clear on subsequent photos at $20.3 \mathrm{~km}$ (e.g. Figs 4 and $5 \mathrm{~b}$ and c). No other surge after 1906 propagated this far.

\section{The 1946/47 surge}

Several observations indicate that a surge occurred around 1947. Miller (1955) pointed out that the lower part of the glacier was smooth and without crevasses in 1946, as it had been in 1942 (Fig. 5C). An oblique photo taken by him from the western side of Russell Fiord on 12 July 1947 shows the lower part of the glacier to be active, with the surge front located somewhere below $17 \mathrm{~km}$. (The oblique angle of the photo precludes a more exact statement.) On a vertical photograph taken on 12 July 1947 the surge front was located around $19.3 \mathrm{~km}$ (Fig. 4). One interpretation is that the surge front had already reached this final position by the time of the 12 July 1947 photo. Another is that it still had $2 \mathrm{~km}$ to go. Then with a front velocity of up to $50 \mathrm{~m} \mathrm{~d}^{-1}$, as observed during the 1982/83 surge (Raymond and others, 1987), roughly 1 month would be required for the final position to be reached. As discussed in the main text, the termination date of a surge is probably influenced by weather, a cool melt season promoting later termination. Because 1947 was cooler than 1983, it is feasible that the termination was later than the early-July termination of the 1982/83 surge. In other words, it is reasonable that the surge could have continued for another month after the 1947 photo was taken. For these reasons we prefer to call this the 1946/47 surge, rather than 1947/48 as suggested by Lawson. 